\title{
Prevalence of Metabolic Syndrome among Subjects attending General Health Checkup of a Tertiary Center of Kathmandu, Nepal
}

\author{
Yagya L Shakya, Shankar Raut, Tirtha M Shrestha, Ram P Neupane
}

\section{Author(s) affiliation \\ 'Department of General Practice and Emergency Medicine, Maharajgunj Medical Campus, Tribhuvan University Teaching Hospital, Institute of Medicine, Kathmandu, Nepal}

\section{Corresponding author}

Tirtha M Shrestha, MBBS, MD tirtha_48@yahoo.com.au

\section{Submitted}

Jan 4, 2021

\section{Accepted}

Mar 31, 2021

\begin{abstract}
\section{Introduction}

Metabolic syndrome is one of the major concerns of modern health causing morbidity and mortality. The metabolic syndrome is the constellation of metabolic disorders - insulin resistance; obesity, dyslipidemia and hypertension that are interrelated which lead to higher risk of cardiovascular disease, diabetes, stroke, atherosclerosis and serious health condition. The study focused on the prevalence of all the metabolic syndrome cases that came to general health checkup (GHC) of Tribhuvan University Teaching Hospital.
\end{abstract}

\section{Methods}

The study was a cross-sectional retrospective study of all cases that came to GHC from July 2019 to October 2019. GHC records files of all patients that came for their general health check-up were used to obtain data that included demographic details and the criteria for metabolic syndrome. Waist circumference, weight, height and blood investigations were sent as a routine examination of the general health checkup. Data analysis was done in Microsoft Excel 2019 and SPSS 20

\section{Results}

Among 311 cases enrolled in our study, 99 (31.8\%) met the revised National Cholesterol Education Program, Adult Treatment Panel III (NCEP ATP III) criteria for metabolic syndrome. Among those with metabolic syndrome, males were $52(52.53 \%)$ and females were $47(47.47 \%)$. Also, 81 (81.81\%) out of 99 cases had decreased HDL ( $<1.03 \mathrm{mmol} / \mathrm{L}$ for males and $<1.30 \mathrm{mmol} / \mathrm{L}$ for females), which was the most common component of metabolic syndrome in the study.

\section{Conclusion}

Metabolic syndrome is present in almost one third of the studied apparently healthy patients coming for general health checkup and it emphasizes on awareness regarding screening for metabolic syndrome.

\section{Keywords}

General health checkup, metabolic syndrome 


\section{INTRODUCTION}

$\mathrm{M}$ etabolic syndrome also known as syndrome $X$, insulin resistance is the constellation of the disorder, which is, defined by World Health Organization (WHO) as a pathological condition characterized by abdominal obesity, insulin resistance, hypertension and hyperlipidemia. There is rise in the atherogenic lipids-triglycerides, apolipoprotein B, low high density lipoprotein (HDL-C), elevation of blood glucose and blood pressure which increases the risk of prothrombotic and proinflammatory states. It is associated with two-fold rise of cardiovascular disease risk and five-fold risk of diabetes mellitus with 30-40 \% high risk of developing diabetes and cardiovascular disease within 20 years depending upon the component of metabolic syndrome. ${ }^{1}$ Although regarded as the disease of Western world initially, now it has become a global health concern with rise of metabolic syndrome even in developing countries. ${ }^{2}$

With rise in metabolic syndrome cases in the South Asian population, it is estimated that $20-25 \%$ of South Asian have developed the syndrome and many are prone to it.3,4 Metabolic syndrome is regarded as the first order risk factor for atherosclerotic complications.

The aim of the study was to assess the prevalence of metabolic syndrome as defined by Revised National Cholesterol Education Program, Adult Treatment Panel III (NCEP ATP III) guideline and determine various component of metabolic syndrome.

\section{METHODS}

The study was cross sectional retrospective study done at General Health Checkup Clinic of Department of General Practice and Emergency Medicine, TUTH. For our study purpose we used the revised criteria for Asian population defined by NCEP ATP III.

Metabolic syndrome is present where there are three or more of the following:

- Waist circumference $\geq 102 \mathrm{~cm}$ for males and $\geq 88 \mathrm{~cm}$ for females (Revised NCEP ATP III for Asians: $\geq 90 \mathrm{~cm}$ for males and $\geq 80 \mathrm{~cm}$ for females)

- Systolic blood pressure $\geq 130 \mathrm{mmHg}$ or diastolic blood pressure $\geq 85 \mathrm{mmHg}$ or antihypertensive medication;

- Fasting plasma glucose $\geq 5.6 \mathrm{mmol} / \mathrm{L}$ or on medication for high blood glucose;

- HDL cholesterol <1.03 mmol/L for males and $<1.30 \mathrm{mmol} / \mathrm{L}$ for females;

- Triglycerides $\geq 1.7 \mathrm{mmol} / \mathrm{L}$

All patients that came for general health check up $(\mathrm{GHC})$ were included in the study. People with chronic renal, hepatic, cardiac, gastrointestinal, skeletal, endocrine disease except diabetes, acute illness and pregnancy were excluded in the study. Data was obtained from July 2019 to October 2019.

General health check medical record files of all patients that came for their general health check were used to obtain demographic data that included age, sex, components of metabolic syndrome which included blood pressure, waist circumference, blood sugar, HDL and Triglyceride and BMI. The data analysis was done in Microsoft Excel and SPSS version 20.

Approval to conduct research was obtained from the Institutional Review Committee of Institute of Medicine, Maharajgunj. Permission was also obtained from the Department to access the hospital records of the patient. All records were kept confidential.

\section{RESULTS}

The age of the study group varied from 15 years to 84 years with the syndrome more prevalent (38.38\%) among the age group of $45-54$ years. One subject from age group 15-24 years also had metabolic syndrome in our study. A total of 311 patients that came for general health check up were included in the study out of which 153(49.19\%) were male and $158(50.81 \%)$ were female. The prevalence of metabolic syndrome in the patients was 99(31.8\%) with $47(47.47 \%)$ female and 52(52.53\%) male according to criteria defined by Revised NCEP ATP III (Table 1).

Similarly, majority of the patients that had metabolic syndrome in our study lived in urban areas with 84 $(84.85 \%)$ out of 99 . In the study, $77(77.78 \%)$ out of 99 cases were obese (BMI more than or equal to 25) and a decreasing trend of the syndrome with decrease in BMI (Table 1).

Majority (92.92\%) out of 99 patients had their waist circumference $\geq 90 \mathrm{~cm}$ in men $\geq 80 \mathrm{~cm}$ in women (Table 2). Also in the study $81(81.81 \%$ ) out of 99 cases had HDL $<1.03 \mathrm{mmol} / \mathrm{L}$ for males and $<1.30 \mathrm{mmol} / \mathrm{L}$ for females, which were the most common component of metabolic syndrome in the study. Over half (52.53\%) out of 99 cases had blood glucose less than $5.6 \mathrm{mmol} / \mathrm{l}$ while only $47(47.47 \%$ ) out of 99 cases had blood glucose more than $5.6 \mathrm{mmol} / \mathrm{l}$ (Table 2).

\section{DISCUSSION}

In our study, the prevalence of metabolic syndrome was in 99(31.83\%) out of 311 cases. Nearly one-third of all the apparently healthy population that came for their general health checkup was diagnosed to have metabolic syndrome. In the study of Sharma et $\mathrm{al}^{5}$, metabolic syndrome was observed in about twofifths $(20.7 \%)$ of the patients according to NCEP criteria. These patients are at high risk of having 
Table 1. Demographic distribution of metabolic syndrome

\begin{tabular}{|c|c|c|c|}
\hline \multirow{2}{*}{ Factor } & \multicolumn{2}{|c|}{ Metabolic syndrome } & \multirow{2}{*}{ Total } \\
\hline & No & Yes & \\
\hline \multicolumn{4}{|l|}{ Age group (years) } \\
\hline $15-24$ & $35(16.50 \%)$ & $1(1.01 \%)$ & $36(11.58 \%)$ \\
\hline $25-34$ & $50(23.59 \%)$ & $8(8.08 \%)$ & $58(18.64 \%)$ \\
\hline $35-44$ & $55(25.94 \%)$ & $24(24.24 \%)$ & $79(25.40 \%)$ \\
\hline $45-54$ & $35(16.50 \%)$ & $38(38.38 \%)$ & $73(23.48 \%)$ \\
\hline $55-64$ & $21(9.91 \%)$ & $20(20.20 \%)$ & $41(13.18 \%)$ \\
\hline$>65$ & $16(7.54 \%)$ & $8(8.08 \%)$ & $24(7.72 \%)$ \\
\hline \multicolumn{4}{|l|}{ Gender } \\
\hline Female & $111(52.36 \%)$ & $47(47.47 \%)$ & $158(50.81 \%)$ \\
\hline Male & $101(47.64 \%)$ & $52(52.53 \%)$ & $153(49.19 \%)$ \\
\hline \multicolumn{4}{|l|}{ Residence } \\
\hline Rural & $51(24.06 \%)$ & $15(15.15 \%)$ & $66(21.23 \%)$ \\
\hline Urban & $161(75.94 \%)$ & $84(84.85 \%)$ & $245(78.77 \%)$ \\
\hline \multicolumn{4}{|l|}{ Marital status } \\
\hline Married & $177(83.50 \%)$ & $96(96.97 \%)$ & $273(87.79 \%)$ \\
\hline Unmarried & $35(16.50 \%)$ & $3(3.03 \%)$ & $38(12.21 \%)$ \\
\hline \multicolumn{4}{|l|}{ BMI } \\
\hline Underweight & $25(11.79 \%)$ & $0(0 \%)$ & $25(8.03 \%)$ \\
\hline Normal & $68(32.08 \%)$ & $8(8.08 \%)$ & $76(24.44 \%)$ \\
\hline Overweight & $41(19.34 \%)$ & $14(14.14 \%)$ & $55(17.69 \%)$ \\
\hline \multirow[t]{2}{*}{ Obese } & $78(36.79 \%)$ & 77 (77.78\%) & $155(49.83 \%)$ \\
\hline & $212(68.16 \%)$ & $99(31.83 \%)$ & $311(100 \%)$ \\
\hline
\end{tabular}

Table 2. Components of metabolic syndrome according to NCEP ATP III revised guideline

\begin{tabular}{|c|c|c|c|}
\hline \multirow{2}{*}{ Factor } & \multicolumn{2}{|c|}{ Metabolic syndrome } & \multirow{2}{*}{ Total } \\
\hline & No & Yes & \\
\hline $\begin{array}{l}\text { Hypertension } \\
\text { No } \\
\text { Yes }\end{array}$ & $\begin{array}{c}201(94.82 \%) \\
11(5.18 \%)\end{array}$ & $\begin{array}{l}44(44.44 \%) \\
55(55.56 \%)\end{array}$ & $\begin{array}{c}245(78.77 \%) \\
66(21.23 \%)\end{array}$ \\
\hline $\begin{array}{l}\text { Fasting Blood Glucose } \\
\text { Less than } 5.6 \mathrm{mmol} / \mathrm{l} \\
\text { More than } 5.6 \mathrm{mmol} / \mathrm{L}\end{array}$ & $\begin{array}{c}195(91.98 \%) \\
17(8.02 \%)\end{array}$ & $\begin{array}{l}52(52.53 \%) \\
47(47.47 \%)\end{array}$ & $\begin{array}{c}247(79.43 \%) \\
64(20.57 \%)\end{array}$ \\
\hline $\begin{array}{l}\text { Waist } \\
<90 \text { for male }<80 \text { for female } \\
\geq 90 \mathrm{~cm} \text { in men } \geq 80 \mathrm{~cm} \text { in women }\end{array}$ & $\begin{array}{l}130(61.33 \%) \\
82(38.67 \%)\end{array}$ & $\begin{array}{c}7(7.07 \%) \\
92(92.93 \%)\end{array}$ & $\begin{array}{l}137(44.06 \%) \\
174(55.94 \%)\end{array}$ \\
\hline $\begin{array}{l}\text { TG } \\
\text { TG }<1.7 \mathrm{mmol} / \mathrm{L} \\
\geq 1.7 \mathrm{mmol} / \mathrm{L}\end{array}$ & $\begin{array}{l}158(74.53 \%) \\
54(25.47 \%)\end{array}$ & $\begin{array}{l}31(31.31 \%) \\
68(68.69 \%)\end{array}$ & $\begin{array}{l}189(60.77 \%) \\
122(39.23 \%)\end{array}$ \\
\hline $\begin{array}{l}\mathrm{HDL} \\
\text { Males: } \geq 1.03 \mathrm{mmol} / \mathrm{L} / \text { Females: } \geq 1.30 \mathrm{mmol} / \mathrm{L} \\
\text { Males: }<1.03 \mathrm{mmol} / \mathrm{L} / \text { Females: }<1.30 \mathrm{mmol} / \mathrm{L}\end{array}$ & $\begin{array}{l}81(38.20 \%) \\
131(61.80 \%)\end{array}$ & $\begin{array}{l}18(18.18 \%) \\
81(81.82 \%)\end{array}$ & $\begin{array}{c}99(31.83 \%) \\
212(68.16 \%)\end{array}$ \\
\hline Total & 212 (68.16\%) & $99(31.83 \%)$ & $311(100 \%)$ \\
\hline
\end{tabular}

cardiovascular disease or diabetes mellitus in near future if intervention is not done early. There is a rising trend of prevalence of metabolic syndrome in the Asia Pacific population ${ }^{6}$ and is also a major health concern for countries like Nepal.
In the study, out of 99 patients, the prevalence of metabolic syndrome among male patients was $52.53 \%$ and female was $47.47 \%$. This shows that metabolic syndrome was slightly more common among male than female, which was inconsistent 
with the study of Sinha et $\mathrm{al}^{7}$ and Ramachandran et al. ${ }^{8}$ In their study, higher prevalence of metabolic syndrome was shown among female than male. The study also shows that there was no gender predilection.

In this study, it has been found that the BMI, hypertension, fasting blood glucose, waist circumference, TG and HDL were significantly associated with metabolic syndrome. The waist circumference above $90 \mathrm{~cm}$ in males and above 80 $\mathrm{cm}$ in females was the highest component among the five parameters, which illustrates the trend of increasing $\mathrm{BMI}$ and central obesity. ${ }^{5,9}$

$\mathrm{HDL}$ value $<1.03 \mathrm{mmol} / \mathrm{L}$ for males and $<1.30 \mathrm{mmol} / \mathrm{L}$ for females was the most common laboratory finding in the cases of metabolic syndrome which was similar to the finding by Tamang HK. ${ }^{9}$ Impaired or low function of HDL is associated with prothrombotic and pro-inflammatory state which increases the risk of myocardial infarction and stroke in patient of metabolic syndrome. People with high normal or normal HDL were less susceptible to developing metabolic syndrome. ${ }^{10}$

Healthy lifestyle habits and lifestyle modification forms important aspect of altering metabolic syndrome.11,12 The concept of general health checkup helps identify patients with metabolic syndrome among apparently healthy patients and address those risk factors in the form of life style modifications, physical exercises and use of medications before it can lead to cardiovascular disease or diabetes mellitus.

The limitations of the study is that it used the secondary data from the patient's record files and only included the cases that came to general health checkup rather than screening large apparently healthy population. Because of the retrospective design of the study on subjects attending GHC clinic of a tertiary care hospital, the findings may not be generalizable to the whole Nepalese population.

\section{CONCLUSION}

Metabolic syndrome was present in almost one third of the apparently healthy subjects coming for general health checkup. Truncal obesity and low HDL cholesterol were the most prevalent components of the metabolic syndrome in the population studied.

\section{ACKNOWLEDGEMENTS}

We would like to acknowledge Department of General Practice and Emergency Medicine to conduct research and also Professor Dr. Pratap Narayan Prasad and Professor Dr. Yogendra Man Shakya for their invaluable guidance. Also, we would like to thanks Ms. Amrita Chaulagain for her support and help in preparing the manuscript. We are also thankful to Dr. Jukel Shrestha for his support.

\section{CONFLICT OF INTEREST}

None declared.

\section{REFERENCES}

1. Enas EA, Mohan $\mathrm{V}$, Deepa $\mathrm{M}$ et al. The metabolic syndrome and dyslipidemia among Asian Indians: a population with high rates of diabetes and premature coronary artery disease. J Cardiometab Syndr. 2007; 2(4): 267-275.

2. Vatakencherry RMJ, Saraswathy L. Prevalence of metabolic syndrome among adults in a teaching hospital in Kochi, Central Kerala: a cross-sectional study. J Family Med Prim Care. 2019; 8(6): 2079-2083.

3. Nestel P, Lyu R, Low LP et al. Metabolic syndrome: recent prevalence in East and Southeast Asian populations. Asia Pac J Clin Nutr. 2007; 16(2): 362-367.

4. Eapen D, Kalra GL, Merchant $N$ et al. Metabolic syndrome and cardiovascular disease in South Asians. Vasc Health Risk Manag. 2009; 5: 731-743.

5. Sharma Sk, Ghimire A. Radhakrishnan J et al. Prevalence of hypertension, obesity, diabetes and metabolic syndrome in Nepal. Int J Hypertens. 2011; 2011: 1-9.

6. Ranasinghe $P$, Mathangasinghe $Y$, Jayawardena $R$ et al. Prevalence and trends of metabolic syndrome among adults in the Asia-pacific region: a systematic review. BMC Public Health. 2017; 17: 101.

7. Sinha SK, Goel A, Madaan A et al. Prevalence of metabolic syndrome and its clinical and angiographic profile in patients with naive acute coronary syndrome in North Indian population. J Clin Med Res. 2016; 8(9): 667-673.

8. Ramachandran A, Snehalatha C, Satyavani $K$ et al. Metabolic syndrome in urban Asian Indian adults: A population study using modified ATP III criteria. Diabetes Res Clin Pract. 2003; 60(3): 199204.

9. Tamang HK, Timilsina $U$, Thapa $S$ et al. Prevalence of metabolic syndrome among Nepalese type 2 diabetic patients. Nepal Med Coll J. 2013; 15(1): 50-55.

10. Liu $X$, Tao L, Cao K et al. Association of high-density lipoprotein with development of metabolic syndrome components: a five-year follow-up in adults. BMC Public Health. 2015; 15: 412.

11. Grave RD, Calugi $S$, Centis $E$ et al. Lifestyle modification in the management of the metabolic syndrome: achievements and challenges. Diabetes Metab Syndr Obes. 2010; 3: 373-385.

12. Lee JA, Cha YH, Kim SH et al. Impact of combined lifestyle factors on metabolic syndrome in Korean men. J Public Health. 2017; 39(1): 82-89. 